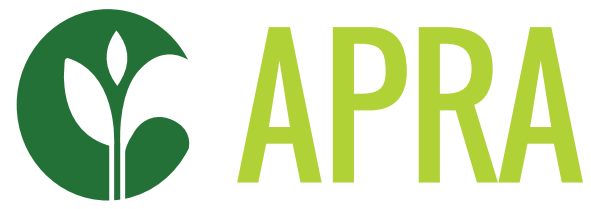

Agricultural Policy Research in Africa

\title{
FROM FIELD RESEARCH TO POLICY CHANGE - LESSONS FROM FAC AND APRA
}

Martin Whiteside

ALRE Working Paper 


\section{CONTENTS}

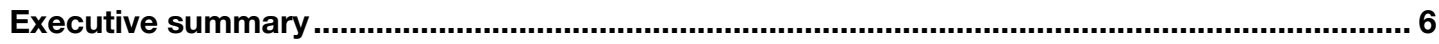

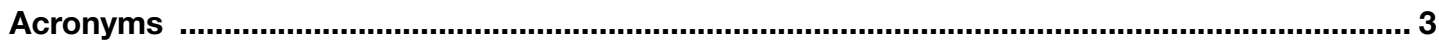

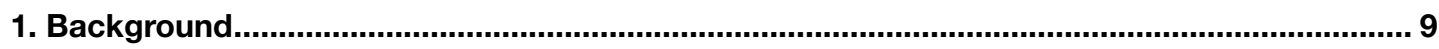

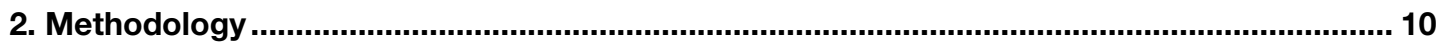

3. Policy influencing lessons from the FAC final evaluation 2014 ...........................................11

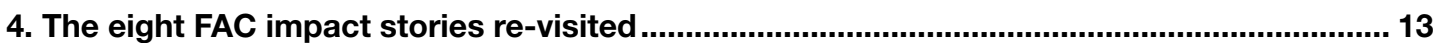

4.1 Co-founding the Land Deal Politics Initiative in 2010 as a global research

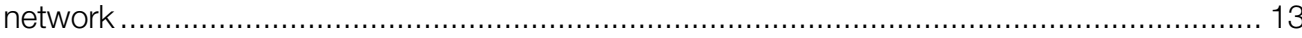

4.2 Institutionalising arid and semi-arid lands policy gains in Kenya..................................... 15

4.3 FAC providing evidence for civil society-led advocacy in Malawi................................... 18

4.4 Evidence influences implementation and maintained donor support for FISP ................. 19

4.5 Deferral of Kenyan Community Land Bill for Extended Consultation ............................... 22

4.6 AU "Drivers of Success in African Agriculture" study and Malabo Declaration ................. 24

4.7 Graduation from the Productive Safety Net Programme (PSNP) in Ethiopia..................... 26

4.8 Adoption of integrated and inclusive seed system and supportive enabling environment

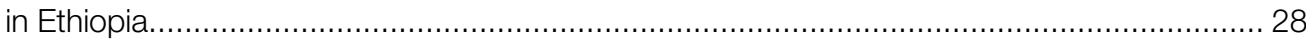

5.Emerging experience from apra policy influencing …............................................................ 32

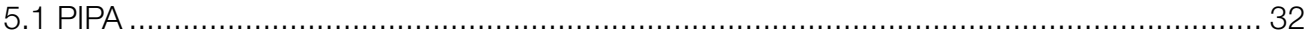

5.2 'Nuggets' of policy critical evidence, blogs, and policy briefs ......................................... 32

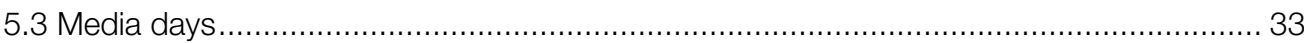

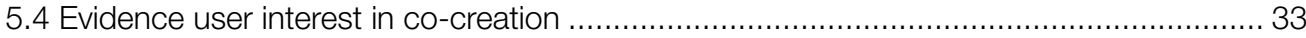

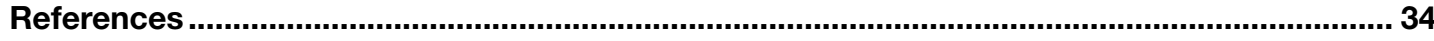




\section{ACRONYMS}

AIP

APRA

ASAL

AU

BENEFIT Programme

BR

CAADP

CDI

CIAT

CISANET

CSO

DCAFS

DFID

EDE

EIAR

ERPI

FAC

FAO

FCDO

FISP

FUM

GLGI

HoS

IDS

IFAD

IFPRI

IIED
Affordable Inputs Programme (of Malawi)

Agricultural Policy Research in Africa

Arid and Semi-Arid Lands (of Kenya)

African Union

Bilateral Ethiopian Netherlands Effort for Food Income

Biennial Review

Comprehensive African Agricultural Development Programme

Centre for Development Innovation (Wageningen University)

International Center for Tropical Agriculture

Civil Society Agricultural Network (of Malawi)

civil society organisation

Donor Committee on Agriculture and Food Security

Department for International Development

Ending Drought Emergencies (Kenyan programming framework

Ethiopian Institute of Agricultural Research

Emancipatory Rural Politics Initiative

Future Agricultures Consortium

Food and Agriculture Organization of the United Nations

Foreign, Commonwealth \& Development Office

Farm Inputs Subsidy Programme (of Malawi)

Farmers Union of Malawi

Global Land Grabs Initiative

Heads of State Ministerial

Institute of Development Studies

International Fund for Agricultural Development

International Food Policy Research Institute

International Institute for Environment and Development 
ISSD

LDPI

LPI

MoA

MDNKOAL

MoLSA

NASFAM

NDMA

NGO

PB

PCANR

PIPA

PLAAS

PSNP

SHA

TOC

VGGT

WP
Integrated Seed System Development

Land Deal Politics Initiative

Land Policy Initiative

Ministry of Agriculture

Ministry of State for Development of Northern Kenya and other Arid Lands

Ministry of Labour and Social Affairs

National Association of Smallholder Farmers of Malawi

National Drought Management Authority

non-governmental organisation

policy brief

Parliamentary Committee on Agriculture and Natural Resources (of Malawi)

Participatory Impact Pathways Assessment

Institute for Poverty, Land and Agrarian Studies (South Africa)

Productive Safety Net Programme (of Ethiopia)

Self-Help Africa

Theory of Change

Voluntary Guidelines

working paper 


\section{ACKNOWLEDGEMENT}

Thanks to all the researchers who worked on Future Agricultures Consortium (FAC) 2005-2014, producing a wide variety of new ideas and policy recommendations. Additional thanks to those team members who engaged with this retrospective analysis, looking at what had changed since FAC closed and was evaluated in 2014. This was a rare opportunity to look at some of the lasting outcomes from a research and policy influencing programme.

Martin Whiteside is an independent environment and rural development consultant with over 40 years' experience in Africa, Asia, Europe and the Caribbean. He led the evaluation of the FAC Programme in 2014 and is currently working on the Accompanied Learning for Relevance and Effectiveness (ALRE) component of the Agricultural Policy Research in Africa (APRA) programme.

This working paper is funded with UK aid from the UK government (Foreign, Commonwealth \& Development Office - FCDO, formerly DFID). The opinions are the authors and do not necessarily reflect the views or policies of IDS or the UK government. 


\section{EXECUTIVE SUMMARY}

The Institute of Development Studies (IDS) has led consortia of UK and African organisations in two large programmes of agricultural policy research: the original Future Agricultures Consortium (FAC) ${ }^{1}$ programme, running from 2005 to 2014, and the successive Agricultural Policy Research in Africa ${ }^{2}$ (APRA) programme, from 2016 to 2022. These programmes involved African field research teams, linked to African Universities, and conducting policy-relevant research into key issues relative to the future of agriculture in Africa (FAC) and inclusive agricultural commercialisation (APRA). A component of both programmes was to use the evidence collected to influence the policy environment in favour of productive, sustainable, and inclusive agriculture.

This paper explores what has been learnt in these two programmes about using field research evidence to improve agricultural policy. In particular, eight case studies of policy change outcomes from the final evaluation of FAC in 2014 were re-visited six years later to confirm whether the initial findings remain valid. Due to COVID-19 restrictions this re-visiting had to be done remotely, which created additional challenges of tracking down key informants and other evidence sources. In addition, emerging lessons on policyinfluencing from the ongoing APRA programme have been incorporated.

Thirteen key lessons are evident from this experience. Many of these are not new, but are worth repeating because experience of these programmes shows their value in practice, and they are often forgotten in the heat of implementation

1. Consider the political economy. Understanding the political economy of the policy, and the practice environment which the new evidence is supposed to be influencing, is essential. A process like Participatory Impact Pathway Analysis (PIPA) (CGIAR, no date) and/or constructing a policyinfluencing Theory of Change (TOC) can be a means of doing this, as long as the political economy power dynamics are considered. Whose interests are likely to be served by better evidence? Who is likely to play an enabling or an inhibiting role? Who are the allies? What are their interests? What are the time-critical moments?

2. Design for demand. Experience shows that demand-led policy-influencing tends to be more effective (with evidence pushing at an open door). Plan the policy influencing process from the start, alongside the research design to ensure there is user demand for the researcherdelivered evidence supply. Early involvement of evidence users with elements of co-design and ownership building is ideal, but may be difficult to fully realise in practice due to timescales involved. Managing supply expectations may be important. The early use and periodic refresh of influencing planning tools, such a PIPA and/or an influencing-orientated TOC, can be helpful.

3. Be demand responsive. Understanding evidence demand is important, as different audiences will need different formats and different emphasis. Timing may be critical: evidence made available at the start of a policy review process may be enthusiastically received, and the same evidence delivered after a policy has been decided may be ignored. Flexible and demand-led planning processes are needed to keep research programmes relevant in terms of both emphasis and timeliness.

4. Work in alliances. Influencing policy involves specific skills, experience, and interests. It is often more effective for evidence suppliers to work in advocacy alliances. Alliances may involve researchers focusing on their comparative advantage in evidence production, while advocacy organisations use the evidence in their influencing. In other contexts, different evidence producers may network together to produce mutually enhancing evidence, across sectors or regions. Alliances may be formal or informal, temporary or longer lasting. Networks

1 Future Agricultures Consortium (FAC) - https://www.future-agricultures.org/

2 Agricultural Policy Research in Africa (APRA) - https://www.future-agricultures.org/apra/ 
may already exist or need building. Organisations like donors, private sector, and national governments can often be advocacy partners in one context and targets of advocacy in others.

5. Be nimble. Despite the best made plans, policy change often does not follow a linear change: process of evidence $\longrightarrow$ communication $\longrightarrow$ policy change. Adaptive planning (being 'nimble') is important to take advantage of changing opportunities, with shifting power and interests of policy change 'enablers' and 'inhibitors', and 'moments' of influencing opportunity. Having flexible funding, being able to respond to issues as they arise, and the opportunity to call on additional organisational and political resources are important and need to be part of the programme design. Providing space for reflection/ discussion/qualitative processes/amplifying voices of change may be critical (policy influencing may be more akin to 'gardening' than 'mechanic' - creating the conditions for change to grow).

6. Institutions matter. Emphasis is needed on the 'how' of implementing policy change and not just the 'what'. Institutions and institutionalisation (of knowledge/thinking/approaches) are important in policy. Understanding the institutional environment for competing policies, competing interests, and the institutional mechanisms for delivery is important. There is a difference between changing 'policy' and getting that new thinking owned, embedded, implemented, and further developed by service sectors, local government, and/or private businesses.

7. Personalities matter. Individuals, positions, and perceptions are part of the solution. New ideas may need to come from the 'right' level of person in the 'right' organisation with the 'right' national ownership. Personal relationships, trust, and perceived integrity of evidence, messenger, and message can be critical. This may involve working with people who straddle the knowledge-policy space, providing them with evidence in the right format and creating the space to reflect, discuss and, when conditions are right, to implement. Identifying, listening, and understanding these key 'change-maker' needs, dedicating time to building relationships, patience, and persistence are all important.

8. Ownership matters. Feeling ownership of evidence and conclusions is important. Policy makers are more likely to use evidence they have had involvement in creating, and are more likely to quote and be swayed by the opinions of farmers they have directly heard themselves. Early identification of end-users, combined with creative research design and appropriate budgeting, may help incorporate evidence users into research planning, evidence generation, on-site experience, and peer review, and thus generate wider ownership and deeper understanding.

9. Add value. Complementing and enhancing existing research, evaluation, or policy reflections and processes can be effective. Examples include complementing existing programme evaluations and/or quantitative data collection exercises with qualitative evidence needed to explain or provide the policy pointers of the other data. Sometimes, this may involve creating space for informal discussion, reflecting on a wider range of data sources, or bringing in perspectives from elsewhere.

10. Use multiple channels. In many cases, policy influencing will require the use of multiple channels of communication using multiple formats through different networks. Presentation and interpretation of evidence is important. Distilling large quantities of research data into policy briefs (PB) and policyrelevant 'nuggets' may be more appropriate than academic papers. Blogs can be a good way of raising and refining issues and stimulating interest. Media days can be effective in enabling popular communication of new ideas and evidence, and can also build longer term relationships in which new evidence can be fed to journalists. These also provide an opportunity for journalists to fact-check new stories with researchers.

11. Build capacity. Resources and time may be needed for capacity strengthening in evidenceled policy change. Influencing skills may include political economy analysis of the policy change context, advocacy planning, networking, and diverse communication approaches. Developing contacts and respect beyond the academic/ research community may be equally important. A scheme like the 'Early Career Fellows' used in FAC provided both coaching and influencing experience that has proved effective in the longer term.

12. Measure what matters. Monitor, measure, and evaluate what really matters. This may mean less emphasis on outputs (e.g., number of publications or number of workshops) and more emphasis on outcomes such as changes in understanding and 
attitudes among key stakeholders, changes in policy, and changes in practice. There may be a need for post-programme monitoring to learn from the actual outcomes and associated lessons from the longer-term use of evidence.

13. Be smart in mainstreaming differences. Think carefully what gender and social difference mainstreaming means in practice. Plan explicitly how to incorporate gender and social difference into both the evidence generation and, crucially, policy influencing. This goes beyond reporting disaggregated data (e.g., by gender or other groups), to understanding (and testing) how policy implications are likely to impact on different groups, and how policy recommendations may be used (and mis-used) by others to pursue different vested interests. 


\section{BACKGROUND}

Which pathways to agricultural commercialisation are the most effective in empowering women, reducing rural poverty, and improving food and nutrition security in Sub-Saharan Africa?

APRA is a six-year research programme of the FAC which aims to address this question through in-depth, interdisciplinary, comparative research across nine countries. Through this work, APRA is generating highquality evidence and policy-relevant insights on more inclusive pathways to agricultural commercialisation.

With headquarters at the IDS, APRA will run from 2016 to 2022 with the generous support of the UK's Foreign, Commonwealth \& Development Office (FCDO).

The APRA programme is supported by the FAC, a partnership of leading African and UK researchers engaged in evidence generation and policy influencing on agricultural policy processes in Sub-Saharan Africa. FAC was supported by the UK's Department for International Development (DFID, now part of FCDO) through a series of accountable and competitive grants from 2005-2014. The Consortium continues to operate, with APRA as its current flagship programme.

This paper uses previous experience from FAC engagement efforts to provide learning on best practice in policy influencing for the benefit of the current APRA Programme. 


\section{METHODOLOGY}

The final evaluation of the FAC covered a six-year period. It included eight impact case stories which were researched and written up in 2014. Some lessons on the links between research generated evidence and policy influencing were identified in that report.

The current study re-visits the case studies after an interval of six years, to look further into any longerterm policy influencing outcomes from the earlier work. For each case study, a series of questions were investigated:

a. What policy changes have taken place since 2014?

b. What are the main drivers of these changes?

c. Has evidence been used in informing or justifying any of these changes - and, if so, what and how?

d. Was any of this evidence contributed to by FAC research or publications - and, if so, what and how?

e. Have the researchers involved with FAC continued to be influential in providing policy advice? If so, who, why, and on what?

f. Are FAC evidence/publications continuing to be used or referred to? If so, what and how is it being accessed and used?

g. Has the capability built by FAC continued to be important in generating policy influencing evidence?

h. What lessons do you think there are for making policy influencing research programmes more effective?

These questions were investigated primarily through a series of email exchanges and some phone calls with key informants. COVID-19 travel restrictions prevented direct face-to-face discussions.

This exercise in following-up outcomes from evidenceinfluencing activities from six years earlier demonstrated the challenges of attempting to do this within COVID-19 restrictions. Contacting busy people remotely who had moved on in their lives proved challenging. In many cases, potential respondents were in lockdown and likely fed-up of engaging in endless Zoom calls with weak connections and eating expensive data packages. Whatever the reason, the degree of input from stakeholders who were not directly involved in the FAC programme was very low. 


\section{POLICY INFLUENCING LESSONS FROM THE FAC FINAL EVALUATION 2014}

The FAC end of programme evaluation produced several recommendations with general applicability to the link between evidence research and policy influencing:

- Invest in an outcome and learning focussed monitoring and learning system with adequate capacity. This could be linked with innovative approaches to measuring and learning about outcome and impact, with a focus on enablers and inhibitors in different contexts.

- Integrate an Early Career Fellowship scheme into the overall programme to maximise the synergy between evidence generation, policy influencing, and capacity building.

- Look into ways of co-creating evidence to ensure relevance and ownership of policy makers and practitioners. Develop institutional mechanisms for end-user input into research generation and peer review.

- Mainstream gender and social difference by developing appropriate organisational systems, including for planning and peer reviewing work, and provide the resources required to back these up.

- There are advantages of researcher-led programmes in terms of flexibility, getting information rapidly into the public domain, convening discussions, and framing debates.

- Flexible and researcher-driven planning processes keep programmes relevant. This may need to be combined with a more rigorous approach to the prioritisation of themes to avoid spreading resources too thinly and ensure adequate reflection, monitoring, adjustment, and follow through.

- Value for money can be enhanced by creating synergy between policy research, communications, and capacity building, and using evidence from policy research to influence policy.
- It is effective to combine African ownership, which is valued by policy makers, with access to global thinking and communications through international partnerships.

- Organisational culture, relationships, and individuals matter and help deliver value.

- To maximise outcomes and impact, policy influencing programmes should focus their contribution on particular policy processes, using their TOC combined with internal political economy analysis of each engagement opportunity, in order to identify their core comparative advantage in relation to other actors. This process should be supported by more explicit and documented cycles of engagement and reflection.

- Communications through new and traditional non-specialist mass media (especially television, which is important for influencing politicians and higher-level policy makers) matters. Invest in communications capacity as this will add value to overall impact.

- Identify and make use of policy influencing 'enablers'. Although these tend to be context specific, some enablers are common across a number of contexts:

- Involvement of dynamic and committed individuals in decision making positions, who are interested in using evidence;

- Availability of pre-existing research evidence and political economy analysis;

- Involvement of experienced and respected capacity to support the process; and

- An appropriate 'moment'.

- Identify and mitigate policy change 'inhibitors'. These inhibitors are context specific but are 
commonly disruptive external events and/or

difficult to influence political systems. Political economy analyses of the influencing context, working with the appropriate people within the system, and being sufficiently nimble to deal with surprises, are useful in reducing the influence of policy change inhibitors. 


\section{THE EIGHT FAC IMPACT STORIES RE-VISITED}

\subsection{Co-founding the Land Deal Politics Initiative in $\mathbf{2 0 1 0}$ as a global research network}

\section{The situation in 2014}

In 2014, the Land Deal Politics Initiative (LDPI) was a platform for generating, highlighting, and discussing political economy evidence on land deals globally for and with policy makers, non-governmental organisations (NGOs), and civil society, and building the capacity of young, largely African, researchers as part of these processes.

LDPI was co-convened in 2010 by FAC along with four other international agricultural research programmes in South Africa, Canada, the Netherlands, and the United States. They perceived that the rising media interest in 'land grabs', fragmented and low-quality responses from academic, policy, and advocacy actors, and the beginnings of multilateral processes to address the issue, presented a moment of opportunity for a more political economy-based approach.

The primary activities of LDPI were: three international conferences on Global Land Grabbing (IDS in April 2011, Cornell in October 2012, and African Union (AU) Land Policy in Africa Conference in 2014); 41 small grants to predominantly young/new/African researchers and research grants to other researchers; and related research outputs: online proceedings, social media, three special issues of the Journal of Peasant Studies, a special issue of Development and Change, LDPI working papers (WPs) and PBs.

Through co-convening the LDPI, FAC significantly contributed to making the land deals policy space one where more evidence-informed positions on land deals policy were being taken by most stakeholders. Political economy evidence that complimented more traditional quantitative macro data, and which prominently included the perspectives of southern researchers, was drawn upon, and showed where policy influencing was needed. LDPI also strengthened the capacity of 41 young predominantly African researchers in political economy research/policy influencing and advanced their career prospects.

FAC's key contributions to the LDPI were fourfold. Firstly, conceiving LDPI as a diverse platform for evidence gathering and engagement that included all the major actors - donors, civil society/NGOs, and southern researchers from the outset, plus the northern researchers traditionally dominating such evidencefocused spaces (e.g., the first global conference had $150+$ participants and over 400 wanting to attend, and LDPI has an international network of 90 researchers). Secondly, making funding available for two rounds of LDPI Small Grants to a relatively large number of primarily young African Researchers to gather fieldbased evidence, engage in land deals policy processes at an international level, and develop their capacity and publishing profile, rather than using the same funds to commission a less diverse and well-established number of mainly northern research consultants (potentially at less risk and management cost). Thirdly, providing communications expertise in websites, press, and social media to document and report on the first Global Land Grabs Initiative (GLGI) Conference in real time and with a significant output that was of a high standard. Finally, dynamic leadership by the FAC Land Theme Conveners (lan Scoones and Ruth Hall) who enabled LDPI to leverage their extensive networks of academic, civil society, and donor actors (especially connected to Africa) to rapidly mobilise and sustain those actors' commitment with resources in kind and access to policy processes.

\section{Outcomes reported in 2014}

In 2014, key informants reported that international NGOs and civil society were taking more evidenceinformed decisions when taking positions on land deals. The GLGI conference provided some of the first field-based research on which civil society could later base its campaigning (e.g., Oxfam UK Land and Power Work). A dent was made in World Bank dominance of policy, but their view was still more important than that of LDPI in this space. This wasn't surprising given that the World Bank discourse was driven by their comparatively much larger research 
spend than FAC. There had been a shift in the nature of multilateral organisation and donor government agency policy debate, and for decision making to be more scientifically informed, because LDPI provided evidence of where attention was needed and of the impact on/getting benefits for communities, and on transparency issues. The AU Land Politics Initiative started working with LDPI researchers (e.g., Land Policy in Africa conference, Ghana; FAC and the Institute for Environment and Development (IIED) and Agricultural Investment, Gender and Land in Africa conference; Land Policy Initiative (LPI) and the Institute for Policy, Land and Agrarian Studies (PLAAS) at the request of the Food and Agriculture Organization of the United Nations (FAO)). Some agribusiness/food companies felt social pressure to pay attention to issues in their value chains or operations and adhere to global norms/ guidelines (e.g., Coca Cola and Pepsi Cola via the Behind the Brands and Grow campaigns of Oxfam UK who were themselves influenced by LDPI research).

\section{How things have moved on since 2014}

The launch of the Voluntary Guidelines (VGGT) in 2012 was a key moment during the FAC period. A review of the guidelines (Hall, Scoones and Henley, 2016), under the auspices of the DFID-funded Land: Enhancing Governance for Economic Development (LEGEND) programme, fed into wider debate within DFID, FAO, and others. The report notes that:

Globally, significant progress has been made on implementing the VGGT. Enormous efforts by diverse actors have laid the groundwork for scaling up initiatives. For a non-binding instrument this widespread support is a key ingredient, but by itself it is not enough. Specific steps taken to enable implementation have been the production of high-quality learning materials - technical guides and e-learning courses - and the convening of training events targeting a broad spectrum of audiences, including policy-makers, practitioners, civil society activists, journalists and others. Less evident thus far is the development of monitoring mechanisms to assess the impact of these initiatives on understanding and uptake of the VGGT. Benchmarking national laws and policies on land, fisheries and forestry against the VGGT is an important next step.
Implementing the VGGT is not a linear process, nor is there any single lead institution. Instead, it is a decentralised process involving diverse institutions with different interests. The past four years have seen new kinds of partnerships among actors that have not previously worked together - for instance civil society and campaigning organisations working closely with private sector actors to strengthen their oversight and governance of their global supply chains.

The complementary debate on land governance around land investments within the $\mathrm{AU}$ was also important and resulted in a number of commitments, following on from the engagement with the Pan-African Parliament around land deals. The links with the AU's LPI (now African Land Policy Centre) resulted in longerterm linkages, particularly with PLAAS and the crossAfrica training programme, the Network of Excellence on Land Governance in Africa (NELGA, no date).

However, in the last five years or so, the heat has gone out of the earlier land deals debate, and attention has switched to a range of new investment trends and wider land governance issues. Current APRA work on corridors and land investments in pastoral areas built on the earlier LDPI work, but extended the discussion to thinking about infrastructure, energy investments, and so on. The immediate collaboration around LDPI gave way in 2016/17 to the Emancipatory Rural Politics Initiative (ERPI) (IISS, no date) (coordinated by the same group, plus Transnational Institute). This initiative focused on how land/resource grabbing and extraction was linked to new forms of authoritarian populist politics. Broadening the networks and building on the LDPI model (small grants, building the evidence base, sharing widely) again proved highly effective, and kept momentum up around the focus on land deals, but in new political contexts, and with a wider geographical base (this is described in a book on the ERPI by Scoones et al. (no date)).

\section{The legacy of FAC and the LDPI in 2020}

The literature and evidence generated through FAC funding have continued to be used at lower intensity ${ }^{3}$ and act as a source material for significant publications. ${ }^{4}$ The networks that formed the basis of

3 For instance, FAC Policy Brief 77, International and Regional Guidelines on Land Governance and Land-Based Investments: An Agenda For African States (Sulle and Hall, 2014) was widely downloaded early on, and had 23 downloads from the FAC website from 2017 to the end of 2020. It is also hosted on a number of other sites, including PLAAS at the University of the Western Cape, South Africa, and therefore may have had more downloads than were recorded through FAC.

$4 \quad$ FAC Policy Brief 77 was cited in FAO (2020) and African Development Bank (2020). 
LDPI continue to have influence and have gone on to work within the ERPI network and beyond. The wider debates raised about land governance have been central to the VGGT guideline implementation. Moving beyond an Africa focus and having links to European, Asian, American, and other networks has been an important development.

Many of the Early Career Researchers supported by LDPI have gone on to be influencers themselves within academic and activist circles.

Overall, while the debate has moved on from the specific preoccupations of the FAC period, the earlier strategic input from FAC remains an important contributor to a dynamic and evolving knowledge and activist process.

\section{Key lessons from FAC's involvement in the LDPI}

- Linking research with advocacy and action through building contacts across researcher/ activist networks is essential.

- Having a flexible funding base, being able to respond to issues as they arise, and build networks, host events, set up small grant programmes, and get things happening was vital and central to the Consortium's success. This flexibility, available through FAC, has been lost under APRA, which has a different funding model. As a result, the follow on from LDPI was not funded through FAC, and ERPI was funded by a different array of supporters.

- There was value in involving Early Career Researchers in building influencing experience and activist contacts beyond 'research'.

\subsection{Institutionalising arid and semi-arid lands policy gains in Kenya}

\section{The situation in 2014}

An important policy influencing opportunity was presented by the creation of a Ministry of State for Development of Northern Kenya and other Arid Lands (MDNKOAL) between 2008 and 2013, led by a Minister committed to using international best practice to promote development and resilience in pastoral areas.

The policy context pre-2008 was founded on a largely negative narrative emerging from colonial and postcolonial divisions of Kenya into high- and lowpotential areas. Investment was to be concentrated on high potential areas, which would develop and support the welfare of those in the low potential areas. The 'low potential' northern areas were not priorities for investment in development, nor were the pastoralist livelihood models considered productive or capable of dynamic development. Meanwhile, the emerging academic narrative was quite different; recognising the development potential of arid- and semi-arid areas, the high value of the meat and milk products generated from pastoralist production methods, and the ability of these systems to adapt to changing market and climate conditions. Researchers with strong links to FAC contributed to this changed academic narrative, in particular with some work on the economic contribution of livestock products to gross domestic product, despite a lack of external investment or political support, which was persuasive.

The 2012 Vision 2030 development strategy for northern Kenya and other arid lands, along with Arid and Semi-Arid Lands (ASAL) Policy, marked a change in tone of Kenyan Government policy documents with a focus on investment, development, realising potential, and transformation.

\section{Outcomes reported in 2014}

Improved policy was developed, and serious attempts were made to institutionalise the new thinking and practice into the post-Ministry period. A wide range of actors and events were involved in this complex and dynamic process.

Clearly, the overriding drivers to the process were the opportunities provided by the new Ministry and the commitment and vision of those involved in it. The wider realisation that 'something had to be done' about northern Kenya amplified by the drought, was built upon years of experience, policy analysis, and civil society advocacy The participants involved in the 2014 evaluation identified the following as contributors to the process:

- The emerging 'best practice' for pastoralist development, contributed to in a small way by FAC researchers, was important.

- Key figures in the Ministry noted the usefulness of what was presented in the FAC-facilitated University of the Bush and the 2011 Pastoralism Conference. This was described as 'creating the climate to enable them to make the case for change.' Although the key figures in ASAL policy development, coming from pastoralist backgrounds, instinctively understood much of 
what the academics were articulating, it was important for them to know what they were proposing was in-line with 'best practice' and helped them defend it to cabinet and other colleagues. Alongside FAC evidence, SOS Sahel, IIED and the Resource Conflict Institute provided a more direct technical assistance role.

- A working group on pastoralism (convened by FAO), ASAL stakeholders forum, and a number of NGOs providing technical input and advocacy on pastoralist issues, are reported to have made use of FAC materials.

- $\quad F A C$ research encouraged the setting-up of the Livestock Marketing Board, which is in the ASAL Policy but had not been gazetted.

- Participation by the MDNKOAL Director of Education in the FAC-organised Future of Pastoralism Conference (Ethiopia, 2011) seems to have contributed to continuing the championing of nomadic education.

- Evidence, which FAC contributed to, on the real financial contribution of pastoralist livelihoods to the national economy, helped reinforce the arguments for a transformed approach, although the extent of this is difficult to assess.

- $\quad$ FAC briefing of Pastoral Parliamentary Group (in Kenya) members increased their understanding of some evidence, but the outcome of this is unclear.

- $\quad F A C$ played a significant role in supporting the documenting of the policy development process and making it available to wider audiences and giving it additional credibility. The FAC grant enabled the writers to spend time on reflection and writing. Although the Ministry 'handover notes' would likely have been produced even without FAC, the quality and dissemination would have been much reduced.

Key lessons at that stage were policy change is not sufficient - institutionalising the change in national plans, budgets, and institutional mandates is also required. Another lesson was that evidence can be particularly influential to reinforce emerging political policy choices and to persuade a committed Minister's cabinet colleagues to come on-board.
How things have moved on since 2014

- With the ending of the MDNKOAL, the ASAL brief passed to the new Ministry of Planning and Devolution in 2013, under the State Department of Devolution. Shortly after this transition, the new Minister initiated a 'review' of the ASAL policy, even though it was barely a year old. It might have been reasonable to revisit it in light of devolution (although it had been revised after the Constitution was passed and devolution was a given).

- The review was conducted by a consultant without, it appears, substantial consultation. It is not clear whether the process was ever completed, with nothing on the Ministry website (the Kenya National Drought Management Authority (NDMA) still refers to the 2012 version - the Sessional Paper passed by Parliament).

- After 2017, Planning moved into the Treasury, and Devolution became 'Devolution and ASALs', with a new Minister. Thus, the ASAL brief gained a slightly higher profile with its own State Department (and consequently its own Principal Secretary).

- It seems the 2013-2017 Ministry did very little with the ASAL Brief, perhaps because the State Department of Devolution had other urgent matters on its plate at a time when the county governments were becoming established and inter-governmental tensions were playing out. The 2017 Ministry has been slightly more active, but has lacked technical understanding and capacity, and it is hard to see how its actions have been advancing the policy.

- Directive from the Head of the Public Service to establish an ASAL Cabinet Sub-Committee, which would then have steered the policy, came just a few weeks before the 2013 elections, and consequently lapsed.

- A positive role has been played by the National Drought Management Authority (for which the ASAL ministry exercises oversight). The Chief Executive Officer and his senior staff, particularly those leading on the Kenyan strategy of Ending Drought Emergencies (EDE), have been committed to the policy and continued to champion it; they talk about the policy and refer to it in documents and public statements. To a 
large extent, the EDE process (which the NDMA leads) has been an implementation mechanism for the policy - particularly its second and fourth objectives (the ASAL enabling environment security, infrastructure, human capital - and climate resilience). The EDE strategy, which has been embedded in both subsequent medium-term plans (2013-17 and 2018-22), draws directly from the policy and the ASAL Vision 2030 strategy. So, even though the cabinet mechanism was not put in place, policy implementation has progressed at a technical level to some extent.

\section{The legacy of FAC in 2020}

FAC WP 68, Creating Space for Pastoralism in Kenya (Elmi and Birch, 2013) ${ }^{5}$, is frequently cited by other researchers writing about the ASALs, and is particularly valuable thanks to the authors' direct involvement in government decision making at the critical time. One of its outcomes (alongside the work of other writers who have worked closely with the government, such as Michael Ochieng Odhiambo) was to convey a more nuanced picture of government policy and thinking in recent years. External observers comment about what governments do and the reasons they think they do it, but government officials rarely put their own thoughts on paper. Examples of citations of WP 68 are:

- The International Development Research Centre's Deconstructing a Pastoralists' Network to Evaluate Climate Adaptation in the Sector: A Case Study of Narok, Kenya (Ngaruiya and Muithui, 2018).

- The International Development Research Centre's Vulnerability and Adaptation to Climate Change in the Semi-Arid Regions of East Africa (Few et al., 2015).

- World Bank's 'Prospects for Livestock-Based Livelihoods in Africa's Drylands' (de Haan, 2016).

- $\quad$ The International Fund for Agricultural Development (IFAD) report, FAO's and IFAD's Engagement in Pastoral Development (IFAD and FAO, 2016).

Other relevant FAC PBs continue to be downloaded from the FAC website at relatively low numbers. ${ }^{6}$

Since FAC closed in 2014, those involved with it have continued to work in different parts of government, or as researchers or consultants - and have therefore been able to continue to build on the FAC experience and relate it to the policy environment.

\section{The lessons from FAC's involvement}

The ASAL policy (alongside the Constitution and the National Land Policy) are referred to as 'framework documents', in that they set a different policy direction and articulate a different set of values (all three marked a significant departure from previous thinking), but their implementation depends on the enactment of subsidiary legislation, the allocation of resources, and technical capacity of others (primarily the sectors and the county governments). This posed a dilemma, as implementation of the policy was, to a large extent, outside the originator's control (even had the Ministry not been disbanded) (Odhiambo, 2015).

Therefore, policy communication is a key lesson, both for policymakers and those who seek to influence them. There are still people working directly on ASAL issues in Kenya, both in government and civil society, who are unaware of the policy or its content. Its approval at the tail-end of the Ministry's life meant there was very little time to disseminate its content. But this should have been done. The NDMA's experience of helping people understand the EDE strategy has been that communication needs to happen at multiple levels and in different ways, and to be repeated; it takes time for these things to percolate into consciousness. It's very hard to achieve sustained policy understanding when key staff are moved around and institutional mandates keep shifting. This is perhaps even more of a challenge for something like the ASAL policy, which requires a shift in thinking and understanding. As such, another lesson is that this is not just about imparting information. It would have been ideal, for example, to have accompanied the policy communication process with something like IIED's Pastoralism and Policy Training Course, which is designed to counter misperceptions about pastoralism and drylands.

The challenges facing the ASALs are not necessarily because of antagonism towards pastoralism, or a lack of understanding about the ASALs, but may simply reflect the general weaknesses of the government. Policies can be approved with minimal reflection on how they affect other policies, resulting in layers of competing commitments. And, without concrete

5 It has been downloaded 728 times from the IDS Open Docs portal, including 60 times between August 2020 and January 2021.

6 For instance, FAC Policy Brief 70, Social Protection in Pastoral Areas (Lind and Birch, 2014b), has been downloaded 13 times since 2017, and FAC Policy Brief 71, Investment in Drylands (Lind and Birch, 2014a), has been downloaded 19 times. 
implementation mechanisms, insufficient attention is given to how policy direction translates into action. A lesson for policy research-influencing programmes is to focus as much on the institutional mechanisms for delivery as on the content of the policy.

Personalities and relationships do matter. Key FAC leaders and researchers invested in building and maintaining relationships, briefing the Minister informally from time to time on their work and keeping in touch. This was contrasted with the behaviour of representatives of some other advocacy organisations who would sit down in the Minister's office and deliver their talking points with little attempt at building a relationship or following up afterwards. Sometimes relations are as important as evidence.

\subsection{FAC providing evidence for civil society led advocacy in Malawi}

\section{The situation in 2014}

FAC had generated evidence, policy framing and analytical input into three civil society organisations (CSOs): the Civil Society Agricultural Network (CISANET), the Farmers Union of Malawi (FUM), and the National Association of Smallholder Farmers of Malawi (NASFAM), as well as the Parliamentary Committee on Agriculture and Natural Resources (PCANR). Working in partnership with these organisations enabled FAC members to concentrate on their comparative advantage of research and analysis, with the CSOs able to use their much larger advocacy capacity and political weight to utilise evidence and analysis from FAC for policy influencing. The 2014 FAC evaluation found 'moments', 'pre-moment capacity', and the building of advocacy relationships to be important drivers for advocacy outcomes. Although assessing attribution in this multi-actor process was difficult, the approach was deemed effective and significant policy influencing opportunities were underway in 2014 , including the revised National Agricultural Policy.

Key aspects of the policy context in 2014 were:

\section{The Farm Inputs Subsidy Programme (FISP),} which was one of the highest profile government policies in the country and is covered in Section 4.4.

The Customary Land Bill. Security of access to customary land was a highly sensitive issue in Malawi, with women in the traditional matrilineal system having significant rights alongside the chiefs' considerable power of patronage - land is the foundation of their powerbase. The concern was that untitled customary land might be more at risk of land grabbing by powerful interests, particularly in areas with irrigation potential. The Customary Land Bill envisaged significant extension of titling, potentially in the name of the household, which may give male household heads more influence, particularly in cases of inheritance or marital breakdown. Chiefs could also see their influence over land removed in favour of Land Committees.

The policy outcome sought by FAC was to provide an analysis on land grabbing by foreign interests, which they did in the context of large-scale irrigation. The tabling of the Land Act provided an unplanned moment and opportunity to inject a political economy analysis into an issue that had not been a particular priority issue for FAC (nor for CISANET, FUM, or NASFAM).

The National Agricultural Policy was a contested issue in Malawi, particularly in relation to the varying support needs of large numbers of smallholders, many cultivating less than a hectare, as against the policy needs of the larger 'commercial' farming sector. As part of the requirements for Malawi to participate in the benefits from the G8 New Alliance for Food Security in Africa Programme, the country was required to develop an Agricultural Policy by June 2014. Due to the elections, this was delayed to March 2015. The policy outcome sought by FAC was to use political economy analysis to encourage the agricultural policy to focus realistically on how to achieve the desired outcomes.

\section{Outcomes reported in 2014}

Between 2009-2012, the political environment was not easy for CSO advocacy work. However, despite this, a number of key informants noted that FAC managed to work quite creatively with its partners during this period.

- $\quad$ FAC research and analysis helped raise concerns about the Land Bill late in the process among CISANET and PCANR, but the Bill was passed by Parliament nevertheless. This was an example of FAC seizing the moment and contributing evidence to the debate, even if rather late and with little policy change impact.

- FAC raised debate in civil society about wider issues relating to the FISP, but fundamental reframing of opportunities to use FISP for agrarian transformation and growth did not occur. FAC contributed evidence and analysis to important critiques of FISP design and implementation, and weaknesses in the Comprehensive African Agricultural Development Programme (CAADP) 
process in addressing alternative processes; but the development of alternative positive ways forward remained under-developed.

- $\quad$ FAC evidence used by CISANET (and probably FUM/NASFAM) potentially influenced National Agricultural Policy through participation in working groups - possibly the most direct FAC influenced outcome. In 2014, it was still too early to judge the outcome from this engagement and the possible impact from any policy and/or practice change achieved.

\section{The legacy of FAC in 2020}

There is a discrepancy between the assessment of the previous Chair of the PCANR and FAC researchers on the degree of continuing influence of FAC. The previous chair considers use of FAC evidence, publications, and their legacy influence has been minimal since 2014. FAC researchers, however, assess FAC influence and evidence that use has continued. Some evidence provided for this is:

- Over the past six years, NASFAM, FUM, and CISANET have, at times, been part of the formal governmental and donor decision-making 'roundtable' processes. This enabled FAC evidence and recommendations to be presented and used within these.

- In academic circles, evidence generated by FAC has been used and strengthened by other researchers - thus building new capability for both agricultural research and building capacity for further influence.

- A legacy of FAC is the networks of researchers built under it - they have kept in touch, which led to collaboration in other research activities, one of which is APRA.

- Some Early Career Fellows supported by FAC have continued to use the experience gained through the programme in their research activities, including the principle of using research to influence policy. The FAC experience also promoted new relationships among researchers. For instance, it was through FAC that Loveness Msofi came into contact with her PhD supervisors, Ruth Hall at PLAAS and John Thompson at IDS, and also worked with other experienced Malawian researchers, such as the late Ephraim Chirwa and Blessings Chinsinga. She has now joined the APRA Malawi Team.
- Choosing the right topic for the moment to produce and communicate evidence proved critical. An example of this was FAC WP 46, Climate Change and Agricultural Policy Processes in Malawi (Chinsinga, Chasukwa and Naess, 2012). This has been downloaded 640 times (21 in the last six months) and was also cited by the United Nations Conference on Trade and Development report Harnessing Agricultural Trade for Sustainable Development (UNCTAD, 2020).

The lessons from FAC's involvement in civil society led advocacy in Malawi

The importance of working with and through coalitions and alliances:

- Donors. There were occasions where researchers could not directly engage with government or technocrats, but the same information went to the government through donors, such as the Donor Committee on Agriculture and Food Security (DCAFS), which drew on and shared FAC evidence when engaging with the government.

- Civil society. In addition, even though some government engagement with CSOs was considered by some to be just for window dressing, key coalitions such as CISANET, NASFAM, and FUM proved to be an important channel for FAC information. The researchers stated that if they had just taken evidence directly to the government, it would not have been as influential.

- Presenting the right topic at the right time. If a Ministry or donors are reviewing policy, evidence may be very welcome. If a policy has just been approved, then evidence, especially if it challenges the agreed policy, is likely to be ignored.

\subsection{Evidence influences implementation and maintained donor support for FISP}

\section{The situation in 2014}

The FISP was one of the highest-profile government policies in the country - comprising about 70 per cent of the Ministry of Agriculture (MoA) budget, featuring in the election pledges of all the political parties, and was strongly influenced by a succession of Presidents. FISP grew out of the 2001/02 drought and food crisis which caused enormous suffering and necessitated large scale and expensive food imports. There were early versions - the 'starter pack' and 'Targeted Input Programme' from 1998 to 2004 - supported by a 
previous regime which, for political reasons, FISP needed to be different from.

FISP was supported by the rural majority but tended to be opposed by the private sector. It was a contested area for the donor community. Although the relatively favourable rains pre-2014 contributed, FISP was credited with eradicating the need for food imports and became the 'Poster Boy' for successful support for smallholder farmers in Africa. The reality was more complex, as analysed in a book by FAC researchers (Chirwa and Dorward, 2013).

The main evidence contributing to the FISP change process was a series of annual independent evaluations commissioned by DCAFS, funded by DFID and implemented by SOAS University of London/Wadonda Consultants. However, the key evaluators were FAC members, and Future Agricultures also financed some qualitative information collection alongside the quantitative collection funded by DFID. Moreover, FAC supported the publication and communication of a number of policy documents and a number of workshops/conferences arising from the evaluations.

\section{Outcomes reported in 2014}

Research activity funded and published through FAC, by the team who eventually won the evaluation tender, was considered to be a contributor to their successful bid. Having won, modest co-funding by Future Agricultures supported qualitative data gathering and communication of the evaluation results, which proved very effective in leveraging limited FAC funds.

The main FAC communications impact within Malawi seems to have been through analysis and presentations given by Future Agricultures members at a number of civil society conferences and policy dialogues. FAC publications seem to have been less well-used (except by some key people in CISANET, FUM, and NASFAM who referred to them in their advocacy and engagement efforts). Sadly, the key MoA staff were not aware of key FAC publications that might have been useful to their work. More focus on distributing paper versions of key reports may have helped. With limited resources within FAC for direct policy dialogue with the government, resourcing key CSOs who had a seat on various government policy development tables was an effective strategy.

A key contribution of FAC has been to take evidence and policy analysis from FISP and communicate it internationally. This appears to be successful. Evidence from the FISP evaluations have been published in a number of peer-reviewed journals and presented to a number of influential organisations, including FAO, the Alliance for a Green Revolution in Africa, the Regional Strategic Analysis and Knowledge Support System, DFID, IFAD, the Organisation for Economic Cooperation and Development, the Netherlands' Ministry of Foreign Affairs, the Kenyan Government, and the AU Commissioner for Rural Economy and Agriculture. It is difficult to say how many of these presentations would have been made by FISP evaluators without any links to FAC.

FAC also funded the purchase and distribution of 200 paperback copies of the book Agricultural Input Subsidies: The Recent Malawi Experience (Chirwa and Dorward, 2013). This resulted in the Oxford University Press publishing the book in paperback for sale in Africa at a much lower price than the hardback price, and has enabled wider use of the book in Malawi in particular. The book was also available as a PDF file under open access arrangements, with around 1,000 downloads from over 20 countries (Malawi being the country with the most downloads) in the first six months of publication alone.

\section{How things have moved on since 2014}

Until 2012, although the government resisted advice from research and evaluations, donors and civil society continued to engage the government using this evidence. The death of President Bingu wa Mutharika in 2012 changed the dynamics. New President Joyce Banda's administration (2012-2014) was more willing to listen and act accordingly, especially since people were not content with the socioeconomic situation in the country. There was still an obsession with the FISP and its centrality in the social-political contract between the government and citizens. There were attempts to expand the programme to include nonbeneficiary farmers through the Farm Input Loans Programme. Selectively, the government implemented some of the research recommendations, for instance, reducing the scale of the programme from about 1.5 million beneficiaries to 900,000 beneficiaries to increase its sustainability; although the gains from such savings were never explicitly accounted for in alternative investments in agriculture.

ThePeterMutharika presidency (2014-2020) responded to donor calls to increase farmer contributions from MK500 to MK3500, and later MK7000. Private sector retailing of fertilisers under the FISP programme was also implemented, with the objective of improving the efficiency of delivery of the programme and enhancing the private sector's participation. The consequences 
of these changes were bad - the programme was captured by private interests and the debate on its sustainability continued.

In response to concern over climate change, FISP was scaled down 1.5 million to 900 thousand recipients. It was argued this was a huge investment and, if the season/weather was not good, there would be large losses - although the savings achieved were not translated into programmes supporting irrigation as was hoped.

This experience influenced the thinking and discourse of the 2019 presidential campaign that FISP was not viable, and therefore that alternative options were needed. This led to the significant changes of Lazarus Chakwera presidency's Affordable Inputs Programme (AIP) 2020 - which targets all farming families (no sampling needed) and will see coupons no longer used. Instead, biometric data linked to the National Identification system is to be used to purchase the inputs, which is expected to reduce capture of the programme as, previously, some retailers were presenting redeemed coupons merely bought off the farmers. Only cereals are being supported (sorghum, maize, rice); whereas legumes were previously included in the programme. Nevertheless, questions of impact remain: whether providing the inputs to every smallholder farmer will increase fertiliser efficiency and realised output, and around the challenge of the overall fiscal impact.

\section{The legacy of FAC in 2020}

There are differing views on the degree of remaining influence from FAC in FISP/AIP. One of the politicians most involved considers that the evolution of FISP has been driven by political considerations, with little use of evidence and little reference to FAC publications. Meanwhile, the researchers involved consider FAC's legacy to be significant, while acknowledging the overriding influence of politics.

The download information shows considerable continuing reference to FAC evidence. For instance, FAC WP 39, 'The Political Economy of Agricultural Policy Processes in Malawi: A Case Study of FISP' (Chinsinga, 2012), has had 2220 downloads, with 187 of these in the last six months.

The FISP academic debates post-2014 were triggered by evidence generated by FAC and the FISP evaluations, but there have been different factors at different points driven by political context that have hindered or promoted uptake of evidence. The high profile of FISP in the turbulent residential campaigns since 2012 demonstrated political economy in action, but meant that more nuanced evidence derived from detailed research perhaps took a backseat in comparison to winning votes and satisfying short-term fiscal constraints.

FAC work and the evaluations are among great resources on FISP in Malawi. For instance, the concept note and background documentation on the current AIP was drawn from the FAC evidence.

In 2020, when political parties outside the government wanted to present alternative proposals for agriculture, especially because the current programme was not delivering, the FAC work became important. Some FAC members were asked by political parties to contribute agricultural policy suggestions to their manifestos - an opportunity to fuse FAC thinking into policy alternatives. Although the outcome, like the current AIP, may be more populist than suggested by the evidence, the general thinking about how these programmes could be done better was provided. The opportunity for this was the work done under Future Agricultures politicians were looking for people with expertise and knowledge, and this resulted in some FAC members being asked to contribute. In addition, when the Centre for Multiparty Democracy conducted sessions with political parties prior to the 2019 campaign to help them conduct evidence-based campaigning, food security featured highly, and FAC evidence and Future Agricultures members were used.

\section{The lessons from FAC's involvement in the FISP}

Persistence. FAC researchers continued producing evidence, despite sometimes receiving negative reactions from technocrats and politicians. They made sure the message was repeated, and new nuances were made; and they learned in the process the need to tailor messages for different audiences and purposes. Some of this evidence and learning was used many years later in the 2020 election.

Leveraging supporting further analysis and communication on the back of a series of evaluations involving large scale data collection proved effective. The DFID partnership enabled FAC to include pertinent FAC evidence into the dialogue.

Four levels of engagement proved effective and complementary: 
Direct engagement by individual FAC members and teams. This was made possible because the implementers of the evaluators also happened to be FAC members.

Identification and creation of fora for dialogue and debate. Principally through CISANET and their Policy Dialogue events.

Production and communication of FAC knowledge products and services. Principally FAC publications; more hard copy availability might have added value among Ministry staff.

Encouraging others to be catalysts in policy debates and alliances. With more local communication resources (for example, the press) there might have been more opportunities to build capacity through evidence and to connect with less conventional alliances, like the Private Sector (Malawi Confederation of Chambers of Commerce and Industry) - perhaps on the growth potential of FISP.

There was a view that participants got tired of the same people, presenting similar papers in comparable formatted conferences, in similar hotels. Perhaps there is a need for the academics to step out of their comfort zone and try various approaches with different participants?

\subsection{Deferral of Kenyan Community Land Bill for Extended Consultation}

\section{The situation in 2014}

The evaluation case study was chosen because of advocacy driven by dissatisfaction among pastoralist leaders and civil society, informed in part by FAC research, about pastoralist land rights within the draft Kenyan Community Land Bill. Pastoralist parliamentarians achieved a deferral and extended consultation with community stakeholders. At the time of the evaluation in 2014, the Bill had just returned to parliament accompanied by a report on the consultation.

Under colonial law, pastoral land was vested in a Native Lands Trust Board - even though, in practice, most pastoral and common property lands continued to be utilised in customary systems and were administered by customary institutions. The postindependence Constitution conferred far-reaching powers to Parliament and the President to alienate trust lands, thereby extinguishing rights provided under customary law.

After 1999, there was a paradigm shift in the policymaking and legislative processes with regard to pastoralism. Kenya began to recognise pastoralism and community rights over land and resources existing therein. The 2010 Constitution provided for community land which was held by communities identified on the basis of ethnicity, culture, or similar communities of interest. In 2009, the new Land Policy changed 'trust land' to 'community land' and the allocation of its title to a particular community group. Community land boards elected by communities themselves were to manage access to land. Despite this recognition, there remained an array of anomalies and inconsistencies in some provisions of the land bills that formed the framework for implementing the constitutional provisions related to community land.

A new Land Act (2012) was mainly concerned with lands that are designated as public or private; it has very little to say about 'community' lands and, while it had implications for community land, it did not elaborate how community land was to be handled - which was a weakness as it was supposed to be a guide to the other bills in identifying the different categories of land tenure regimes and their management processes.

The Community Land Bill (2011), introduced alongside the Land Bill, provided for the allocation, management, and administration of community land and the establishment of Community Land Boards. However, according to FAC research, it had significant weaknesses:

- It failed to build upon existing customary land institutions and instead prescribed what these institutions should be.

- Community authority to elect/appoint members to the Administration Committees and Community Land Boards was not entrenched.

- There was not an identified legal process for establishing community ownership of 'trust lands'.

- It does not elaborate provisions for conversion of land from private or public to community, and vice versa, nor does it provide a framework for recognition, protection, and management of community lands (Letai, 2014). 
FAC researchers contributed valuable and unique research evidence to the land issue. The degree to which this evidence had been used in the legislation drafting process remained unclear. FAC had some excellent, respected, and committed researchers that touched upon important aspects. However, FAC did not have the institutional footprint to be a significant policy-influencing force on what was a contentious issue with strong vested interests.

Although a PB critiquing the Community Land Bill was drafted in 2012/13 and used for briefing the Pastoralist Parliamentary Group in draft form, it was not formally published until July 2014. The delay seems to have been in getting comments from theme leads and peers. This reduced its potential usefulness, particularly by third parties who were unaware of the draft paper. By the time the PB was published, the stakeholder consultation on the draft bill had returned to parliament - and there was a need for a short new critique on what was being re-presented to parliament. This illustrates that FAC's procedures (including unpaid peer review) and timetables are more appropriate to the research world than the fast-moving rough and tumble of the advocacy world.

This suggested FAC did not have the capacity for sustained stand-alone advocacy, and that this was not its comparative advantage. FAC would have benefitted from a clearer strategy of providing the research evidence and political economy analysis to be used by more dedicated and better resourced advocacy organisations. This did happen to an extent, and was valued, but could have been more effective if it had been a more explicit strategy (e.g., see Malawi Case Study of FAC working in partnership with CISANET).

The core work of FAC researcher John Letai was based in specific areas on land deals, with a basic focus of informing policy on how land deals were impacting on the social economic status of communities. This did not directly relate to the land reform agenda in Kenya based on the Community Land Bill, but broadly helped inform policy makers of the deals that are taking place and how they impact on communities. The information was valued by those advocating on land legislation issues, but many involved were unaware of the connection with FAC, which is an indication of the light institutional footprint of FAC. This is a consequence of the very modest funding provided by DFID - and the focus by FAC on using the limited funds to support research and researchers rather than build an advocacy institution.
The Community Land Act came into force in 2016, with salient features (Mainnah, 2016):

- Community Land is vested in the community, which is defined as an organised group of users of community land who are citizens of Kenya and share common interests, but not necessarily common ethnicity.

- Community land may be held under customary, freehold, leasehold, or other arrangements.

- $\quad$ Customary land rights are given equal footing in law as freehold and leasehold.

- Community land can be converted to public or private land and vice versa, with two-thirds community member approval.

- Management by the Community Land Management Committee.

- A County Government holds in trust unregistered community land and is prohibited from selling, disposing, transferring, and converting for private purposes unregistered community land that it is holding in trust on behalf of a community.

- A registered community may use alternative dispute resolution mechanisms, including traditional dispute resolution mechanisms to settle disputes.

It seems that many of the shortcomings, highlighted by FAC documentation in 2014 (Letai, 2014), have been achieved, at least in theory. While the new law is considered positive and even cutting-edge in some respects, legal loopholes still place communities at risk of their lands not being as secure as promised ahead of formalisation, and at risk of losing some of their most valuable lands during the formalisation process (Wiley, 2018). However, it is not clear how influential FAC research and advocacy was in achieving this change.

\section{The lessons from FAC's involvement in the Kenya land debate}

- Timing is important in advocacy: a critical FAC publication was published after key legislative steps had been taken.

- Advocacy capacity and profile is important. This could have been delivered more effectively by 
an explicit partnership approach, with evidence provision being the comparative advantage of FAC.

- There is a need for post-research project monitoring to understand the actual outcomes and associated lessons from the longer-term use of evidence.

\subsection{AU "Drivers of Success in African Agriculture" study and Malabo Declaration}

\section{The situation in 2014}

FAC attempted to engage formally with CAADP institutions in order to strengthen CAADP policy processes, although these efforts failed to gain significant traction until 2013. At this time, FAC's Political Economy Theme Convenor was invited to participate in the 'Drivers of Success' in African Agriculture study, commissioned by the AU Commission, in anticipation of the 'Year of African Agriculture in 2014' and following the 10th anniversary of the 2003 Maputo Declaration. This study covered seven countries (Ethiopia, Tanzania, Malawi, Rwanda, Ghana, Sierra Leone, and Nigeria) and involved a number of researchers from FAC's network. It was completed in November 2013 and shared with senior officials and African Agricultural Ministers both incountry and in various continental meetings, leading up to the AU Heads of State Ministerial (HoS) in June 2014 which resulted in the Malabo Declaration. The Drivers of Success study catalysed considerable energy from senior officials and agricultural ministers by bringing to the fore a political, rather than a purely technical, understanding of why some countries are meeting their AU/CAADP commitments while others are falling behind. Under this momentum, the Declaration of the $\mathrm{AU}$ HoS meeting restated and extended its CAADP commitments for the coming decade. This engagement brought FAC's particular frame of analysis into the CAADP institutional process, garnering interest from both the AU Commission and member states and laying the groundwork for FAC country researchers to be involved in future policy analysis and capacity building.

\section{Outcomes reported in 2014}

The AU Commission perceived the Drivers Study to have been critical in influencing their own thinking, as well as that of Agricultural Ministers and Ministry staff building up to the AU Head of State meeting. A key change had been the inclusion of an explicitly political analysis in the Drivers study, in what has been previously a very technical, target-driven discourse. This immediate shift came about through discussions between the ALINE research team and the AU in June 2013. At that point, the combination of countries and the inclusion of political drivers (for improved policy/ public management capacity) was agreed. However, the longer-term work of FAC in this area clearly had an influence. The AUC was very engaged and excited by this 'new' emphasis.

The extent to which the findings of the study are reflected in the actual declaration of the Heads of State is perhaps less clear. According to ALINE, the link is clear - e.g., the association made in the Declaration on productivity gains being primarily from increases in yield vs. cultivated land area. While there may have been other sources for the content of the AU declaration, this study was certainly the most substantial piece of analytical work carried out by CAADP institutions, to inform the collective thinking and commitments of African governments on agricultural policy and strategy going forward.

The political economy piece (contributed by FAC's Colin Poulton and country researchers) is the most complicated aspect of the study and 'how that played a role in reaching the right people to get right decisions'. ALINE felt that, at the level of AU Commissioners and in the Declaration itself, some strides had been made. Although some of the messages are perhaps not new, the fact policy makers were now receptive to them was. Perhaps timing has been critical here, since some countries had only been seriously engaging with CAADP in the last three to four years.

When the synthesis study was first presented at the meeting with agriculture ministers in Ethiopia in November 2013, there was also a very positive response. As one key informant noted: 'People for the first time believed that CAADP processes were actually working. CAADP is a qualified success. Principles behind investment and growth, investments in making inputs and new varieties available, Ethiopian extension investment [is working]. ${ }^{8}$ ' Similarly, a new energy and engagement was catalysed by the study in subsequent meetings of Ministers of agriculture and in the CAADP partnership Platform in Durban.

$7 \quad$ Key informant interview.

8 Key informant interview. 
However, as all informants were keen to emphasise, the 'proof of pudding is in implementation' and the extent to which, coming out of Malabo, African leaders take the message back to their countries via press conferences, cabinet meetings, etc. At that stage, it was considered unrealistic to expect any changes in policy or approach from AU political process to have filtered through into the CAADP technical institutions or to country level, so the long-term impact from the commissioning of this study remained to be seen.

\section{How things have moved on since 2014}

The Malabo Declaration put in place a continent-wide performance framework and country disaggregated biennial reporting framework. The 2019 'Biennial Review Report' (BR) shows that this is being taken seriously and with a willingness to name individual countries both negatively and positively:

\section{Conclusions and Main Highlights of the 2019 BR Report (African Union, 2019):}

- The Malabo Declaration was adopted in 2014. AU Member States were required to have developed compliant National Agricultural Investments Plans (NAIPs) by 2018, as key instruments for implementing programmes to deliver on the seven Malabo Commitments. Unfortunately, not all Member States have completed this process. This has contributed significantly to the continent not being on-track to meet the Commitments. There is a need for urgent action on this.

- The BR continues to inspire wide interest and dialogue on agricultural transformation in Africa, as desired by the Malabo Declaration. Both the BR process and resultant Africa Agriculture Transformation Scorecard and the Malabo BR Dashboard are key instruments for facilitating the peer review mechanism enshrined in the $A U$ principles and original New Partnership for Africa's Development (NEPAD) Agenda.

- Over two BR cycles, it has been observed that Member States with relatively advanced national data systems that are well-integrated with other reporting mechanisms at national, regional, and global levels, generally produce better quality BR reports.

- The results of the Second BR Report indicate that the continent is not on-track to meet the goals and targets of the Malabo Declaration by 2025, but positive progress is being made. In this second report, only four Member States are on-track, compared to 20 Member States in the inaugural report in 2017. Overall, progress has been made by Member States, but at a slower than required rate.

- $\quad$ Ghana is the only country that moved from being not on-track in the first BR to being on-track in the current BR report. Conversely, 17 Member States regressed from being on-track to not on-track.

- Several Member States were unable to report on some indicators because they did not have the data in their national agricultural systems. For example, only 19 out of 22 Member States were able to report on reduction of post-harvest losses and the proportion of women empowered in agriculture, respectively; yet these issues are key components in the Malabo Declaration.

- $\quad$ Six Member States did not report on any of the 47 indicators. These are: Algeria, Comoros, Egypt, Libya, Sao Tome and Principe, and Saharawi Republic.

- It is important to note that even though climate change and climate variability pose a significant threat to agricultural transformation in Africa, overall, the continent is not on-track regarding the indicators related to climate change resilience. Serious attention should be given to this issue to ensure that appropriate coping mechanisms are in place to respond to these shocks.

- The Member States have not fully expedited the implementation of the CAADP process, which is fundamental to the adoption and domestication of the Malabo Declaration. Similarly, Member States are performing poorly on the key Commitment of increasing investment finance in agriculture, with all the Member States that reported not on-track.

\section{BR 2019 Awards:}

1. The Malabo BR Gold Award to the Best Overall Score: to the Republic of Rwanda.

2. The Malabo BR Silver Award to the Second Best Overall Score: to the Kingdom of Morocco.

3. The Malabo BR Bronze Award to The Third Best Overall Score: to the Republic of Mali.

4. The Malabo BR Award of the Most Improved in Scores from the preview review: to the Republic of Tunisia. 
5. The Malabo BR Award of the Best Performance in the Theme of the Year "Building Resilience and Livelihoods": to the Kingdom of Morocco.

6. Special Mention to the Republic of Ghana: the only country that moved from not on-track in the inaugural BR to on-track in the second BR.

CAADP insiders consider that the definition of the results framework was made possible by policy research. This helped define what CAADP really was and informed the current direction. It is considered that the CAADP implementation approach can be traced back to the Drivers Study, which was instrumental to re-orientated CAADP.

\section{The legacy of FAC in 2020}

The changes in the CAADP from programme to process, along with a greater emphasis on evidence, is clear. However, any attribution to FAC is extremely difficult to assess. The Drivers Study seems to have been important, but FAC-linked researchers were only part of the consultancy team, and this was not a formal part of the FAC programme. Those involved within the AU/CAADP at the time have largely moved on, are difficult to contact, and their memories of the role of FAC alongside other influencers are not clear.

Some of the FAC publications linked to this piece of work have continued to be downloaded and referred to, which is an indication of their continued relevance and influence. For instance, FAC WP 42, The Political Economy of Agricultural Extension in Ethiopia: Economic Growth and Political Control (Berhanu, 2012), has been downloaded 5,520 times, including 323 times in the last six months of 2020.

\section{The lessons from FAC's involvement in the} Drivers of Success Study and Malabo Declaration

This case illustrates an important distinction between engagement which is 'researcher driven' versus 'demand driven'. After a year or two of FAC failing to gain significant traction with AU/CAADP institutions, the commissioning of the Drivers Study and involvement of FAC researchers in this came about through a 'demand driven' process, which itself came about through a lot of behind-the-scenes networking. It clearly illustrates how existing policy networks and long-standing relationships can influence whether and how research is commissioned to influence processes. In this case, not only did engagement between researchers and policy makers happen in advance of the research being carried out, but also the shape of that research was significantly influenced by that engagement. This perhaps suggests that, going forward, FAC can usefully invest more in 'networking' of this kind and being aware of and responding to and/or building demand for timely evidence, through this process.

The case study also illustrates the importance of 'African ownership' of research on policy processes to achieve traction with country governments, as well as a conscious attempt to build this. This research was commissioned by the $\mathrm{AU}$ and carried out (at country level) by teams of African researchers (27 in total). While the ALINE/SOAS/TANGO (technical assistance to NGOs) leads played a significant role in conceptualisation, facilitation (mainly ALINE), and refining and synthesising findings for presentation and publication, the AU lead and country teams played a prominent role. Backstopping and coaching of the African policy makers and researchers appears to have happened organically as part of this process, keeping the role of the external researchers somewhat in the background (in-line with ALINE's philosophy).

There are wider 'ownership' questions for FAC. Should FAC be increasingly institutionalised and branded as an African-led organisation? Or should there be more ownership by existing African partner institutions, with FAC playing more of an informal networking role? Or is the current contracting, quality assurance, and institutional home of IDS helpful? Is a mixed and flexible approach better, or is this not sustainable in the longer term?

\subsection{Graduation from the Productive Safety Net Programme (PSNP) in Ethiopia}

\section{The situation in 2014}

The Government of Ethiopia implemented PSNP from 2005, with the objective to 'graduate' millions of chronically food insecure Ethiopians to productive livelihoods, supported by donors including DFID, the World Bank, and the United States Agency for International Development. By 2010, the graduation debate had become polarised, between the Government's desire to meet targets set in its Growth and Transformation Programme at all costs and a donor consensus that graduation requires a solid evidence base.

In 2010, FAC's Growth and Social Protection Team began a new project, aiming to broaden understanding of social protection requiring both long-term safety nets for the most vulnerable, as well as flexible interventions to support food insecure people to develop sustainable 
livelihoods. Drawing on an 'enablers and constrainers' graduation framework, research was undertaken with households and communities in four districts each of two regions in Ethiopia, in 2010-2011, to deepen understanding of their perceptions and experiences of graduation. Results from this research were shared with regional and district officials, as well as NGOs and donors, and subsequently published as a FAC WP, and later in journal articles.

FAC's research on social protection in Ethiopia has been one of a number of influences on thinking about 'graduation', in the research as well as donor communities. The research grew out of, and has, to some extent, shaped IDS and FAC Ethiopia researchers' involvement in the biannual evaluation of the PSNP, conducted jointly with the International Food Policy Research Institute (IFPRI) on behalf of government and the donors. In turn, these evaluation findings fed into donor dialogue with the government about modifications to existing, and the design of, future policy and programmes. The real extent to which government positions on graduation and social protection have shifted were expected to become more apparent when the design of the next phase PSNP was finalised in 2014. In early 2014, it was difficult to discern a direct policy impact of FAC's work in this area.

FAC also contributed to the development of capacity in the country to provide high-level consultancy services to design and evaluate social protection policies and programmes.

\section{Outcomes reported in 2014}

In 2011, FAC's global vision of the Growth and Social Protection theme was that, 'by 2015, people involved in conceptualising, planning, implementing, and evaluating social protection programmes, think about graduation differently - "beyond graduation". More specifically, we are seeking a change from "old thinking" about graduation that stresses "exit" and "crossing thresholds" to "new thinking" that focuses on sustainability and resilience - sustainable graduation.'

FAC's involvement in PSNP was to:

- Understand the complexity of food insecurity context by encouraging adoption of our 'enablers and constrainers' framework to analyse and assess the graduation impacts of PSNP.

- Influence PSNP to focus on graduation for those with the ability to graduate, and safety nets for the poorest who are unable to graduate.
A key opportunity from Future Agricultures was the flexibility to use FAC resources to look at interesting and more qualitative issues alongside the more rigid IFPRI quantitative evaluation of PSNP. However, FAC resources were relatively small and not institutionalised, so it was possible to insert ideas and help with thinking, but difficult to make an independent impact. Nevertheless, the work on 'enablers' and 'constrainers' to graduation was viewed as innovative and important.

\section{How things have moved on since 2014}

- 2014/15: Social protection policy developed and approved.

- 2016: Social protection strategy developed (an ex-FAC researcher was one of a three-person team that drafted it and reviewed the translation into Amharic).

- There have been delays in the establishment of two institutional frameworks proposed in the policy - (i) the Social Protection Council and (ii) the National Social Protection Fund, as well as the commitment to universal old age pension for elders.

- 2020: On the International day of Older Persons 2020, the Minister of Labour and Social Affairs announced that the government had finalised preparations to establish the Social Protection Council and the National Social Protection Fund. The non-contributory old age pension is also under discussion.

- 2020: The PSNP IV (2020-2025) is in its final stage of preparation. Donors' commitment is strong, despite the programme making little progress in graduation. Donors see the programme as a 'safe haven', as it is relatively well managed, reviewed every six months, ${ }^{9}$ and an impact assessment is undertaken every two years.

\section{The legacy of FAC in 2020}

Attribution is difficult to ascertain. Governments are often reluctant to acknowledge work done by others. FAC was never institutionalised in Ethiopia (or anywhere else). It operated as a loose network of like-minded researchers and practitioners, initially in three countries and then expanded to 15+. When Future Agricultures operated in Ethiopia, its work was compared to that of IFPRI (including the unfortunate similarity of their

9 The Joint Review \& Implementation Support is held twice a year (Nov/Dec and May/Jun) and has not missed a session until this pandemic came. 
logos), but FAC was not institutionalised. However, some of the issues evidenced and amplified by FAC have become institutionalised within the PSNP, with FAC influence evident in the livelihood component and the move away from the previous concentration on graduation by 2018 .

In Ethiopia, the evidence constituency was very large, covering policy makers, researchers, academics, and practitioners in the public and private sectors at federal and regional levels. Even after several years, there are many who remember the workshops and training FAC conducted and recount the deliberations. These are individuals who have moved on since their engagement with Future Agricultures, but the research findings and policy insights are part of their institutional memory.

In addition, individuals associated with FAC are still active in the field and continue to engage and influence. When FAC started the social protection agenda, agencies were just beginning to talk about the safety net, which was implemented by the MoA. The Ministry of Labour and Social Affairs (MoLSA) was not active in this process. In one of the FAC meetings, it was said that the MoLSA had come out of the shadows to lead the sector. It is not exactly there yet, but it is making good progress. Several institutions (UNICEF, World Bank) have come on board to make social protection a reality.

FAC researchers helped build local capacity on an individual basis and established a local consultancy company that has continued to provide services to PSNP and others. They now feel able to undertake complex consulting assignments relating to social protection. A well-known consultant and researcher, Demese Chanyalew, who completed a consultancy for FAC Ethiopia, published a book in which he acknowledged the work he undertook for FAC as a source of insight (Chanyalew, 2015).

FAC's thought contribution was that graduation was not an 'on/off' issue - what is critical are the livelihood pathways to graduation, and that different households and different circumstances may need different pathways - different enablers and constrainers. This thinking was evident in the response to the 2017/18 drought. FAC provided the space to use qualitative approaches, think, and discuss these issues.

Some of the FAC publications have had significant downloads and continued influence. For instance, FAC WP 23, Transforming Livelihoods for Resilient Futures: How to Facilitate Graduation in Social
Protection (Sabates-Wheeler and Devereux, 2011), has had 1,028 downloads, including 68 in the last six months of 2020 .

\section{The lessons from FAC's involvement in the PSNP}

Institutionalisation of knowledge is key but it needs the right policy environment. Institutionalisation has its own drawbacks - even in a free environment - as institutions have structures that do not allow new ideas to develop as freely as one would like.

Flexible funding provided space for FAC to investigate key emerging issues like graduation of households from the safety net programme. Many were starting to recognise that graduation wasn't working, and FAC had the flexibility to provide discussion spaces to amplify voices coming from within and without the PSNP on this issue. Working with people within the programme provided big changes for a small investment.

There is a need for prolonged, sustained engagement, working with people who straddle the knowledgepolicy space, and providing them with evidence in the right format and the space to reflect and discuss. FAC interventions were not short-term one-offs in a complex policy process, but involved multiple phases of in-depth data collection and analysis, and the provision of policyrelevant insights directly to state actors and those who sought to inform and influence them (e.g., civil society groups, donors, international agencies). This required long-term commitment, strong partnerships between local and international researchers, and flexible funding to allow the teams to test ideas, create and seize new opportunities, and establish and maintain relationships with influential actors who took their advice and evidence seriously (because they were seen as trusted and respected sources).

\subsection{Adoption of integrated and inclusive seed system and supportive enabling environment in Ethiopia}

\section{The situation in 2014}

In 2009, Ethiopia's cereal seed system was based on central planning, with no recognition of informal seed systems, or of the role of markets in seed distribution. However, this system was not functioning effectively, meaning farmers were unable to access quality seed when needed. FAC's work on seeds in Ethiopia has contributed significantly to the decentralisation and liberalisation of the cereal seed system in the country. Key changes have included: the establishment of 
regional seed companies; the successful piloting of direct seed marketing to farmers; the development of independent regulatory authorities; and the adoption of a new Seed Proclamation in 2013. FAC's pioneering research on the political economy of the cereal seeds system in 2010, was a timely and distinct contribution to the policy debate in a context of grain seed shortage and endemic low productivity. In 2011, FAC supported an International Workshop on seed systems organised by the Ethiopian Institute of Agricultural Research (EIAR), which provided a forum for the main stakeholders in the country to share their existing knowledge, thus creating a shared 'evidence base' to inform new policy. FAC also brought experts from its wider network in Malawi, Kenya, and Zimbabwe, to share learning from their seed systems and highlight key lessons for Ethiopia. The lead FAC researcher on seeds in Ethiopia, who is based at the EIAR, has been highly effective in networking and influencing policy processes informally via direct engagement in discussions in the Agriculture Ministry, and numerous consultancy assignments. Most notably, he has been an adviser to the Integrated Seed System Development (ISSD) project run by Wageningen University's Centre for Development Innovation (CDI), financed by the Dutch government, which has pioneered direct seed marketing in the four main regions of Ethiopia and is widely acknowledged as having the largest single influence on changes to the cereal seed system. FAC has provided strategic support to the emergence of this programme in Ethiopia and, in 2014, was engaged in a wider partnership with CDI to scale up this programme in various African countries.

\section{Outcomes reported in 2014}

FAC's work on seeds in Ethiopia made a significant contribution to influencing the development of the seed policy and wider seed system in the country, encouraging a move towards a more decentralised and liberalised system which recognises both private and public actors, and informal and formal actors.

There was effective and wide dissemination of two key pieces of research nationally and internationally, through a major workshop which engaged a large number of stakeholders and brought together a body of evidence to inform future policy making on the seed sector in Ethiopia. FAC's capacity to make linkages with work in other countries also brought comparative experience to the attention of policy makers in Ethiopia.

The focus on the political economy of the seed system was very timely and filled a gap not being addressed by others, in a context where the government was looking for solutions to a major challenge of grain seed shortage and low productivity. The work on this theme in Ethiopia is a good example of effective application of a political economy approach to a specific policy gap or challenge. This perhaps points to a way forward for FAC.

FAC has leveraged important influence from relatively limited resources, via effective networks and partnerships. FAC was effective in collaborating with other actors in the seeds sector at several levels - from NGOs working with farmer organisations to senior level policy makers in the Federal government. Links have also been developed with wider African institutions and internationally, mainly by the theme convenor, but increasingly also involving the FAC seeds researcher from Ethiopia. FAC's involvement as a partner in the new Comprehensive ISSD pilot programme is one major unintended outcome from the work to date.

The influencing model has been indirect as well as direct, supporting the broader and deeper influence of the ISSD programme. The changes to policy and practice described above would not have come about through FAC's influence alone: identifying a strategic partner with the legitimacy and capacity to directly influence wider policy processes paid dividends. FAC has played an important role in supporting the efforts of the ISSD and the different actors associated with this to understand the 'big picture,' the interests of different actors, and how to make change happen in a complex policy environment. FAC's analysis has also helped the Dutch-funded programme overcome challenges and move beyond its focus on local seed systems to a more strategic level. The wider vision and experience of John Thompson as theme convenor with AU and CAADP institutions, and FAC's scope of work across several countries, also has supported the development of the current ISSD Africa partnership.

FAC also worked closely with other organisations, notably Self-Help Africa (SHA), in developing analysis, and tools to support farmer-led and community-based seed systems. Learnings from these pioneering efforts are now being scaled up in wider initiatives, and Dawit Alemu is also centrally engaged in these processes - for example, in his work on the Community Seed programme for the Agricultural Transformation Agency.

IDS and FAC Ethiopia research on the political economy of seeds (in general and in relation to Ethiopia), and its wide dissemination through a special issue of the IDS Bulletin including the paper The Political Economy of Cereal Seed Systems in Africa's Green Revolution (Thompson and and Scoones, 2011) and numerous 
WPs and PBs on FAC website, has been a catalyst to the development of partnerships with SHA and CDI. For CDI, the Political Economy of Seeds paper was 'instrumental in shaping their thinking around ISSD and Political Economy of Seeds.' This paper was 'what made them decide to partner with FAC.' The political economy approach, adapted by FAC, underlies the appeal of this work to actors working on the ground wanting to scale up their efforts and influence wider institutions and processes.

Dawit Alemu's position as a senior researcher and Head of the Department of Agricultural Extension, Agricultural Economics and Gender in the EIAR, has positioned him very well to engage both formally and informally with government stakeholders - up to Director level. He has regular contact with, and expresses his views on key policy issues directly to, such policy makers. Dawit's position gives him a strategic vision of the seed system and its challenges. His institutional position, as well as personal qualities, have been critical to the credibility and relevance of the FAC Ethiopia seeds research and its success in gaining traction in policy processes and programmatic interventions. His skills as an individual researcher and his capacities in networking and collaboration, have also contributed to the success of the work. In addition, as a result of the 'capacity building' support Dawit received through his engagement with FAC, including intensive mentoring and peer review processes, he has been introduced to and integrated a political economy approach to his research and gained insights into experiences of other countries, as well as feedback from his peers in those territories. The inclusion of his publications on the FAC website has also earned him an international profile and afforded him recognition as a leading specialist on these issues.

\section{How things have moved on since 2014}

There have been changes in the leadership of MoA, which has affected the policy processes in the seed sector. However, the policy debates have continued over the years with new leaderships, and different policy documents have been drafted and approved where ex-FAC researchers have been actively engaged:

- $\quad$ New guiding document for the MoA, Transforming the Ethiopian Seed Sector: Issues and Strategies (Alemu et al., 2019), under the Chairmanship of Dawit Alemu;

- A new Ethiopian seed law passed in February 2020;
- Establishment of a National Seed Advisory Group, that is providing regular advice to the policy makers and on which Dawit is serving as a chairperson.

- The BENEFIT Programme, which built on the ISSD work and was influenced by FAC's seeds work. BENEFIT - a multi-million Euro programme - worked to institutionalise integrated seed approaches at a national scale, with Dawit Alemu as Director.

\section{The legacy of FAC in 2021}

The FAC facilitated a national conference and compiled the outputs in the form of a book, The Defining Moments in the Ethiopian Seed System (Asnake et al., 2012). In 2021, it still serves as a key information source and policy reference, and is considered the single most important publication on seed systems in Ethiopia.

Researchers engaged in the FAC seed work are still actively engaged in the national debates related to seeds. Dawit has continued to work on seed-related research and development activities, and is currently Chair of the National Seed Advisory Group established by the MoA in 2019.

The facilitation work of the FAC Ethiopia team in bringing different seed stakeholders together has remained valuable, together with the timely sharing of evidence and documentation that has continued to be available.

The reports published by the seed programme continue to receive significant numbers of downloads:

- IDS Bulletin, The Political Economy of Ethiopian Cereal Seed Systems: State Control, Market Liberalisation and Decentralisation (IDS, 2011), has had 1,030 downloads, with 32 in the second half of 2020 .

- $\quad$ FAC WP 36, Farmer-Based Seed Multiplication in the Ethiopian Seed System: Approaches, Priorities \& Performance (Alemu, 2011), has had 1,900 downloads, with 25 in the second half of 2020.

- $\quad$ FAC WP 17, The Political Economy of Ethiopian Cereal Seed Systems (Alemu, 2010), has had 3,530 downloads, with 68 in the second half of 2020. 
The lessons from FAC's involvement in the

\section{Ethiopian seed sector}

The effectiveness and specific contribution of FAC through its political economy approach:

- FAC leveraged important influence from relatively limited resources, via effective networks and partnerships. The identification of strategic partners (especially CDI and the ISSD Project) amplified the influence and relevance of FAC.

- People matter. The FAC Ethiopia team comprises good background, experience, and moral authority, and are able to conduct research, identify and utilise policy influencing opportunities, align with relevant stakeholders to engage and influence at timely occasions, and ensure recognition and acceptance. Dawit's position as a senior researcher and Head of the Department of Agricultural Extension, Agricultural Economics and Gender in the EIAR, has allowed him to engage both formally and informally with government stakeholders. In 2021, he continues to be influential as Chairperson of Ethiopia's National Seed Advisory Group.

- The timely sharing of policy and development evidence in different formats (WPs, PBs, journal articles, and a locally-produced book) is important.

- Sustained effort can increase impact. FAC had a comparative advantage in the seed sector as one of the pioneers in Ethiopia, but FAC funding ended while the seed reform process was still ongoing.

- A weakness of the FAC approach on seeds in Ethiopia was the limited ability to invest in capacity building, resulting in a narrow cadre of researchers to take seed work forward and ensure its continuity. The FAC thematic work on seeds in Ethiopia has been reliant on one key individual, but he has sustained his influence. 


\section{EMERGING EXPERIENCE FROM APRA POLIGY INFLUENGING}

\subsection{PIPA}

The PIPA process was originally developed by Boru Douthwaite and colleagues at the International Center for Tropical Agriculture (CIAT). It involves stakeholder analysis that describes the existing researcher communicator - policy maker pathways, and identifies the need for additional or strengthened relationships, pathways and networks necessary to achieve a particular goal. CIAT PIPA planning workshops take place over several days and require extensive inputs from programme members and other stakeholders. However, the PIPA approach, as used by APRA, has been modified to enable a rapid version which can fit into a half-day workshop.

The APRA PIPA process was planned at key stages of the programme - during the Inception Phase (early 2017) and revisited at the mid-point (March 2019), with a final reflection towards the end of the programme in order to:

- Help the research team to think about impact, engagement and communications activities, so that these become fully embedded in the project work from the beginning.

- $\quad$ Focus on the changes we want our research to help bring about, and the changes in knowledge, attitude and skills required to support this among key actors and participants.

The PIPA steps included:

1. Defining the vision. What are the big aims and objectives over the long-term? What would we really like to see change as a result of APRA's research and engagement efforts?

2. Developing outcome logic model for scaling out and up:

- Identify key actors (who APRA wants to influence?).

- List changes required to achieve the vision (what practices, knowledge, attitudes, policy does APRA want to change?).

- Propose strategies (how does APRA make the change happen?).

3. Mapping key actors (APRA and partners) and their relative influence on scaling-out and scaling-up APRA outputs. From the actor network map, the PIPA stakeholders reflected on:

- What changes need to occur to allow us to meet the programme's aims?

- What are the main obstacles (people, institutions, processes, practicalities) to influencing policy and practice?

- What are the most effective ways of effecting change?

- How will these come about (actions to take)?

Mid-term PIPA workshops included teams developing TOC that linked the findings which seemed to be arising from their early research results, with the bigger picture of APRA-expected outcomes and impact.

What was innovative in APRA's use of PIPA was the early development of the policy influencing plans, at the start of the research process and continued refinement at key stages forthwith.

\section{2 'Nuggets' of policy critical evidence, blogs and policy briefs}

By the halfway point of the research programme, it was clear that research teams were generating large quantities of evidence. This is clearly of interest to academics and a useful contribution to the stock of knowledge available.

A challenge to teams was to identify those pieces of evidence that were critical to influencing the 
policy change processes necessary to deliver the APRA bigger picture of inclusive and sustainable commercialisation, and how to articulate the evidence to ensure it was accessible to decision makers.

To meet this challenge, the concept of 'nuggets' of policy critical evidence was developed. This encouraged teams to distil their emerging evidence into clearly articulated policy maker-relevant soundbites. It proved a useful discipline to continuously challenge teams on 'What are your nuggets?', 'Who is the nugget for?', 'Why is it relevant to them?', and 'How will you communicate it?'. During the COVID-19 crisis, this 'nugget coaching' was continued in Zoom meetings between research, communications, and accompanied learning teams.

This emphasis on identifying policy critical evidence and demanding relevant recommendations needs to be carried forward into the publications output of APRA. Understandably, researchers are often more comfortable in writing 'supply-driven' research WPs detailing their findings, rather than translating these into 'demand-driven' policy recommendations. This was reflected in an initial tendency to match each APRA supply-driven WP with a PB. A contribution of the 'Impact, Communication and Engagement' and 'Accompanied Learning on Relevance and Effectiveness' teams is to encourage the PBs to be more focussed on demand, perhaps combining the findings from several WPs, and even work streams, into more demand-focussed outputs.

The process of researchers writing blogs has been helpful in enabling research teams to write less formal outputs that they perceive of being of interest. This has been an area of growing capacity and success in APRA. Some blogs are downloaded in their thousands and widely read. They also allow teams to test ideas and present works in progress which, in turn, helps them refine their thinking and the formulation of key messages.

\subsection{Media days}

Previous programmes tended to communicate research results to a combination of academics and policy makers, with the press invited, particularly if the Minister opened the conference (although the media coverage was usually about what the Minister said rather than the research results!). The APRA Tanzanian team experimented with a day-long workshop specifically for members of the media - with emerging research results specifically presented to them. This proved a successful formula, with significant coverage of key messages in print, radio, and TV. It also built contacts between the reporters and the researchers, which has generated further media contacts and exposure. This media-focussed approach has been replicated in other countries where APRA is producing evidence with similarly successful outcomes.

\subsection{Evidence user interest in co-creation}

Mid-term engagement with evidence user stakeholders suggest that some at least would like to be involved in an earlier stage in the choice, design, and evidence collection. It seems that evidence ownership by stakeholders can be an important driver of evidence use. This was also confirmed in some of the FAC case studies. Some of the stakeholders keen to cocreate evidence were CSOs, farmer organisations, and local government officers. This suggests that early opportunities for co-creation could be explored when incorporating future evidence into policy programmes. 


\section{REFERENGES}

Abidjan: African Development Bank. Available at: https://www.afdb.org/en/documents/rethinking-land-reformafrica-new-ideas-opportunities-and-challenges (Accessed: 8 July 2021)

African Union (2019) Second Biennial Review Report of the African Commission on the Implementation of the Malabo Declaration on Accelerated Government Growth and Transformation for Shared Prosperity and Improved Livelihoods. Addis Ababa: African Union. Available at: https://au.int/en/documents/20200212/second-biennialreview-report-african-union-commission-implementation-malabo (Accessed: 8 July 2021)

Alemu, D. (2010) The Political Economy of Ethiopian Cereal Seed Systems: State Control, Market Liberalisation and Decentralisation. FAC Working Paper 17. Brighton: Future Agricultures Consortium. Available at: https:// opendocs.ids.ac.uk/opendocs/handle/20.500.12413/2342 (Accessed: 8 July 2021)

Alemu, D. (2011) Farmer-Based Seed Multiplication in the Ethiopian Seed System: Approaches, Priorities and Performance. FAC Working Paper 36. Brighton: Future Agricultures Consortium. Available at: https://www.gov.uk/ research-for-development-outputs/fac-working-paper-36-farmer-based-seed-multiplication-in-the-ethiopianseed-system-approaches-priorities-and-performance\#citation (Accessed: 8 July 2021)

Alemu, D., Simane, Y., Zeray, T., Ayana, A., Hassena, M., Bishaw, Z., T/Wold, A., Kabato, B., Zewdie, S., Weyema, A., Admassu, M., Wakjira, D., Gezahegn, F., Biruk, D. and Simane, B. (2019) Transforming the Ethiopian Seed Sector: Issues and Strategies. Addis Ababa: Ministry of Agriculture. Available at: https://issdethiopia.org/2019/11/22/ transforming-the-ethiopian-seed-sector-issues-and-strategies/ (Accessed: 8 July 2021)

Berhanu, K. (2012) The Political Economy of Agricultural Extension in Ethiopia: Economic Growth and Political Control. FAC Working Paper 42. Brighton: Future Agricultures Consortium. Available at: https://www.gov.uk/ research-for-development-outputs/fac-working-paper-42-the-political-economy-of-agricultural-extension-inethiopia-economic-growth-and-political-control\#citation (Accessed: 8 July 2021)

Chanyalew, D. (2015) Ethiopia's Indigenous Policy and Growth: Agriculture, Pastoral and Rural Development.

Chirwa. E., and Dorward, A. (2013) Agricultural Input Subsidies - the Recent Malawi

Experience. Oxford: Oxford University Press. Available at: https://www.future-agricultures.org/wp-content/ uploads/pdf-archive/Chirwa\%20and\%20Dorward\%20-\%20Malawi\%20input\%20subsidies\%20book\%20OUP. pdf (Accessed: 8 July 2021)

Chinsinga, B. (2012) The Political Economy of Agricultural Policy Processes in Malawi: A Case Study of the Fertilizer Subsidy Programme. FAC Working Paper 39. Brighton: Future Agricultures Consortium. Available at: https://assets.publishing.service.gov.uk/media/57a08a9be5274a31e00006a6/FAC_Working_Paper_039.pdf (Accessed: 8 July 2021)

Chinsinga, B., Chasukwa, M. and Naess, L.O. (2012) Climate Change and Agricultural Policy Processes in Malawi. FAC Working Paper 46. Brighton: Future Agricultures Consortium. Available at: https://www.gov.uk/ research-for-development-outputs/fac-working-paper-46-climate-change-and-agricultural-policy-processes-inmalawi\#citation (Accessed: 8 July 2021) 
Consultative Group on International Agricultural Research (CIGAR). (no date) 'Participatory Impact Pathway Analysis (PIPA)' [online]. Available at: https://cgspace.cgiar.org/bitstream/handle/10568/33649/11.5\%20 Participatory\%20impact\%20pathway\%20analysis.pdf?sequence=1 (Accessed: 8 July 2021)

de Haan, C. (2016) Prospects for Livestock-Based Livelihoods in Africa's Drylands. Washington, DC: World Bank. Available at: https://openknowledge.worldbank.org/handle/10986/24815 (Accessed: 8 July 2021)

Elmi, M. and Birch, I. (2013). Creating Policy Space for Pastoralism in Kenya. Brighton, UK: Future Agricultures Consortium. FAC Working Paper 68. Brighton: Future Agricultures Consortium. Available at: https://www. gov.uk/research-for-development-outputs/fac-working-paper-68-creating-policy-space-for-pastoralism-inkenya\#tcontents (Accessed: 8 July 2021)

FAO (2020) Extraterritorial Investments in Agriculture in Africa: The Perspectives of China and South Africa. Rome: Food and Agriculture Organization of the United Nations. Available at: http://www.fao.org/3/cb1106en/ CB1106EN.pdf (Accessed: 8 July 2021)

Few, R., Satyal, P., McGahey, D., Leavy, J., Budds, J., Assen, M., Camfield, L., Loubser, D., Adnew, M. and Bewket, W. (2015) Vulnerability and Adaptation to Climate Change in the Semi-Arid Regions of East Africa. Ottawa: International Development Research Centre. Available at: https://idl-bnc-idrc.dspacedirect.org/ handle/10625/57427 (Accessed: 8 July 2021)

Hall, R., Scoones, I. and Henley, G. (2016) Strengthening Land Governance: Lessons from implementing the Voluntary Guidelines. LEGEND State of the Debate Report 2016. Available at: http://repository.uwc.ac.za/xmlui/ bitstream/handle/10566/4113/Hall_Strenghtening-the-land_2016.pdf?sequence=1\&isAllowed=y (Accessed: 8 July 2021)

IDS Bulletin (2011) 'Special Issue: The Politics of Seed in Africa's Green Revolution' IDS Bulletin 42(4). Available at: https://onlinelibrary.wiley.com/toc/17595436/2011/42/4 (Accessed: 8 July 2021)

International Fund for Agricultural Development (IFAD) (2016) FAO and IFAD's Engagement in Pastoral Development. IFAD/FAO, Rome. Available at: https://www.ifad.org/en/web/knowledge/-/publication/fao-s-andifad-s-engagement-in-pastoral-development (Accessed: 8 July 2021)

International Institute of Social Studies (no date) 'The Emancipatory Rural Politics Initiative (ERPI)', International Institute of Social Studies [online]. Available at: https://www.iss.nl/en/research/research-networks/emancipatoryrural-politics-initiative (Accessed: 8 July 2021)

Letai, J. (2014) Kenya's Land Reform Agenda: Pastoralism within the Current Land Debate. FAC Policy Brief 73. Brighton: Future Agricultures Consortium. Available at: https://assets.publishing.service.gov.uk/ media/57a089ceed915d3cfd000438/Policy_Brief_073.pdf (Accessed: 8 July 2021)

Lind, J. and Birch, I. (2014a) Investment in Drylands: Widening the Benefits for Food Security and Development. FAC Policy Brief 71. Brighton: Future Agricultures Consortium. Available at: https://www.future-agricultures. org/publications/policy-briefs-document/investment-in-drylands-widening-the-benefits-for-food-security-anddevelopment/ (Accessed: 8 July 2021)

Lind, J. and Birch, I. (2014b) Social Protection in Pastoral Areas: Promoting Inclusive Growth at the Margins. FAC Policy Brief 70. https://assets.publishing.service.gov.uk/media/57a089f8e5274a31e0000358/Policy_Brief_070. pdf (Accessed: 8 July 2021)

Mainnah, L. (2016) 'A Brief Overview of the Community Land Act No.27', Simmons \& Simmons 14 October [online]. Available at: https:/www.simmons-simmons.com/en/publications/ck0bfc1xho5070b36rrr9wigi/12-abrief-overview-of-the-community-land-act-4fr1ca (Accessed: 8 July 2021) 
Network of Excellence on Land Governance in Africa (NELGA). (no date) 'African Land Policy Centre', Network of Excellence on Land Governance in Africa [online]. Available at: https://nelga.org/nelga-2/alpc/ (Accessed: 8 July 2021)

Ngaruiya, G.W. and Muithui, L.W. (2018) Deconstructing a Pastoralists' Network to Evaluate Climate Adaptation in the Sector: A Case Study of Narok, Kenya. IDRC, Canada. Available at: https://idl-bnc-idrc.dspacedirect.org/ handle/10625/57391 (Accessed: 8 July 2021)

Odhiambo, O. (2015) Securing Community Land Rights in the Kenyan ASALs: Available Legal Options. National Drought Management Authority, Republic of Kenya.

Sabates-Wheeler, R. and Devereux, S. (2011) Transforming Livelihoods for Resilient Futures: How to Facilitate Graduation in Social Protection. FAC Working Paper 23. Brighton: Future Agricultures Consortium. Available at: https://opendocs.ids.ac.uk/opendocs/handle/20.500.12413/2320 (Accessed: 8 July 2021)

Scoones, I., Edelman, M., Borras Jr., S.M., Forero, L.F., Hall, R., Wolford, W. and White, B. (2021) Authoritarian Populism and the Rural World. Abingdon: Routledge

Sulle, E. and Hall, R. (2014) International and Regional Guidelines on Land Governance and Land-Based Investments: An Agenda For African States. FAC Policy Brief 77. Brighton: Future Agricultures Consortium. Available at: https:// assets.publishing.service.gov.uk/media/57a089c940f0b6497400027a/FA-PB77.pdf (Accessed: 8 July 2021)

T/Wold, A. Fikre, A., Alemu, D., Desalegn, L. and Kirub, A. (2012) The Defining Moments in the Ethiopian Seed System. Addis Ababa: Ethiopian Institute of Agriculture Research

Thompson, J. and Scoones, I. (2011) The Political Economy of Cereal Seed Systems in Africa's Green Revolution, FAC Policy Brief 44, Brighton: Future Agricultures Consortium. Available at: https://www.future-agricultures.org/ wp-content/uploads/pdf-archive/Policy_Brief_044\%20(2).pdf (Accessed: 8 July 2021)

United Nations Conference on Trade and Development (2020) Harnessing Agricultural Trade for Sustainable Development: Malawi. Geneva: United Nations Conference on Trade and Development. Available at: https:// unctad.org/webflyer/harnessing-agricultural-trade-sustainable-development-malawi (Accessed: 8 July 2021)

Wiley, L.A. (2018): 'The Community Land Act in Kenya Opportunities and Challenges for Communities', Land 7(1):12. Available at: https://www.mdpi.com/2073-445X/7/1/12/htm (Accessed: 8 July 2021) 
Whiteside, M. (2021) From Field Research to Policy Change: Lessons from FAC and APRA, ALRE Working Paper 1, Brighton: Future Agricultures Consortium

(c) APRA 2021

ISBN: 978-1-78118-836-1

DOI: 10.19088/APRA.2021.019

\section{(cc) BY-NC-ND}

This is an Open Access report distributed under the terms of the Attribution-Non Commercial-No Derivs 4.0 Unported (CC BY-NC-ND 4.0) Attribution - You must give appropriate credit, provide a link to the license, and indicate if changes were made. You may do so in any reasonable manner, but not in any way that suggests the licensor endorses you or your use. NonCommercial — You may not use the material for commercial purposes. NoDerivatives - If you remix, transform, or build upon the material, you may not distribute the modified material. You are free to: Share - copy and redistribute the material in any medium or format.

https://creativecommons.org/licenses/by-nc-nd/4.0/legalcode

If you use the work, we ask that you reference the APRA website (www.future-agricultures.org/apra/) and send a copy of the work or a link to its use online to the following address for our archive: APRA, Future Agricultures Consortium, University of Sussex, Brighton BN1 9RE, UK (apra@ids.ac.uk)

All APRA Working Papers go through a review process before publication.

\section{@creative}

DO YOU HAVE COMMENTS ON THIS PAPER?

We would welcome your feedback on this working paper!

To provide brief comments, please follow this link to our short APRA Working Paper Feedback form: https://goo.gl/forms/1iVnXhhrlGesfR9

Agricultural Policy Research in Africa (APRA) is a programme of the Future Agricultures Consortium (FAC) which is generating new evidence and policy-relevant insights on more inclusive pathways to agricultural commercialisation in sub-Saharan Africa. APRA is funded with UK aid from the UK Foreign, Commonwealth \&

Development Office (FCDO) and will run from 2016-2022.

The APRA Directorate is based at the Institute of Development Studies (IDS), UK (www.ids.ac.uk), with regional hubs at the Centre for African Bio-Entrepreneurship (CABE), Kenya, the Institute for Poverty, Land and Agrarian Studies (PLAAS), South Africa, and the University of Ghana, Legon. It builds on more than a decade of research and policy engagement work by the Future Agricultures Consortium (www.future-agricultures.org) and involves more than 100 researchers and communications professionals in Africa, UK, Sweden and USA. 